Chapman University

Chapman University Digital Commons

$10-7-2019$

\title{
Association Between Socioeconomic Status Mobility and Inflammation Markers Among White and Black Adults in the United States: A Latent Class Analysis
}

\author{
Agus Sarachman \\ The Pennsylvania State University \\ Cara Rice \\ The Pennsylvania State University \\ Bethany Bray \\ The Pennsylvania State University \\ Tara Gruenewald \\ Chapman University, gruenewa@chapman.edu \\ David Almeida \\ The Pennsylvania State University
}

Follow this and additional works at: https://digitalcommons.chapman.edu/psychology_articles

\section{Recommended Citation}

Surachman, A., Rice, C., Bray, B., Gruenewald, T., \& Almeida, D. (2019). Association between socioeconomic status mobility and inflammation markers among white and black adults in the United States: A latent class analysis. Psychosomatic Medicine, 82(2), 224-233. "https://doi.org/10.1097/ PSY.0000000000000752

This Article is brought to you for free and open access by the Psychology at Chapman University Digital Commons. It has been accepted for inclusion in Psychology Faculty Articles and Research by an authorized administrator of Chapman University Digital Commons. For more information, please contact laughtin@chapman.edu. 


\section{Association Between Socioeconomic Status Mobility and Inflammation Markers Among White and Black Adults in the United States: A Latent Class Analysis}

\section{Comments}

This is a pre-copy-editing, author-produced PDF of an article accepted for publication in Psychosomatic Medicine, volume 82, issue 2, in 2019 following peer review. The definitive publisher-authenticated version is available online at "https://doi.org/10.1097/PSY.0000000000000752.

\section{Copyright}

American Psychosomatic Society 


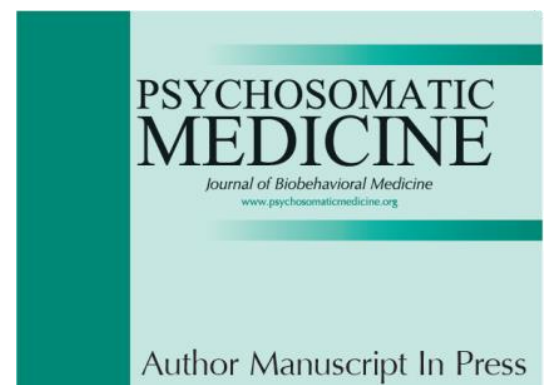

\section{Psychosomatic Medicine}

Author's Accepted Manuscript

Article Title: Association Between Socioeconomic Status Mobility and Inflammation Markers Among White and Black Adults in the United States: A Latent Class Analysis

Authors: Agus Surachman, Cara Rice, Bethany Bray, Tara Gruenewald, and David Almeida

DOI: $10.1097 / P S Y .0000000000000752$

Received Date: December 4, 2018

Revised Date: August 18, 2019

This manuscript has been accepted by the editors of Psychosomatic Medicine, but it has not yet been copy-edited; information within these pages is therefore subject to change. During the copy-editing and production phases, language usage and any textual errors will be corrected, and pages will be composed into their final format.

Please visit the journal's website (www.psychosomaticmedicine.org) to check for a final version of the article.

When citing this article, please use the following: Psychosomatic Medicine (in press) and include the article's digital object identifier (DOI). 


\title{
Association Between Socioeconomic Status Mobility and Inflammation
}

\section{Markers Among White and Black Adults in the United States: A Latent Class}

\author{
Analysis \\ Agus Surachman, $\mathrm{MS}^{1,2}$, Cara Rice, $\mathrm{PhD}^{3}$, Bethany Bray, $\mathrm{PhD}^{3,4}$, \\ Tara Gruenewald, $\mathrm{PhD}^{5}$, and David Almeida, $\mathrm{PhD}^{1,2}$ \\ ${ }^{1}$ Human Development and Family Studies, The Pennsylvania State University \\ ${ }^{2}$ Center for Healthy Aging, The Pennsylvania State University \\ ${ }^{3}$ The Methodology Center, The Pennsylvania State University \\ ${ }^{4}$ Center for Dissemination and Implementation Science, University of Illinois at Chicago \\ ${ }^{5}$ Department of Psychology, Chapman University
}

Corresponding author:

Agus Surachman, MS

Department of Human Development and Family Studies/ Center for Healthy Aging

The Pennsylvania State University

405 Biobehavioral Health Building (BBH) Building

University Park, PA 16802

E-mail: axs527@psu.edu

Phone: 219-413-8253 
Source of Funding and conflict of Interest:

Agus Surachman is supported by the National Institute on Aging Grant T32 AG049676 to The Pennsylvania State University. Since 1995 the MIDUS study has been funded by John D. and Catherine T. MacArthur Foundation Research Network and National Institute on Aging (P01AG020166 and U19-AG051426). Biomarker data collection was further supported by the NIH National Center for Advancing Translational Sciences (NCATS) Clinical and Translational

Science Award (CTSA) program as follows: UL1TR001409 (Georgetown), UL1TR001881 (UCLA), and UL1RR025011 (UW). The authors declare no conflict of interest. 
Abstract

Objective: This paper examines whether multidimensional indicators of objective and subjective socioeconomic status (SES) across the life course can be categorized into latent classes of SES mobility and tests the associations of these categories with inflammation markers among White and Black adults.

Methods: Data are from 592 non-Hispanic White and 158 non-Hispanic Black participants who completed both the baseline survey and biomarkers assessment of the Midlife in the United States (MIDUS) Refresher study. Groups of different SES mobility were examined using latent class analysis.

Results: White and Black participants showed different patterns of SES mobility. Among Blacks, the latent classes were: 1) Objectively Always High (24.71\%; high objective SES across the life course), 2) Subjectively Always High (6.48\%; high subjective and low objective SES across the life course), 3) Downwardly Mobile (35.84\%; high childhood SES, low adult SES, and 4) Always Low (32.97\%; low childhood SES, education, and adult SES). Among Whites, the latent classes were: 1) Always High (52.17\%; high childhood SES, high education, high adult SES), 2) Upwardly Mobile (18.14\%; low childhood SES, high education, high adult SES), 3) Subjectively Downward (27.74\%; high childhood SES, high education, high objective adult SES, low subjective adult SES), and 4) Always Low (1.95\%; low childhood SES, education, and adult SES). SES mobility was associated with inflammation in White (Wald $\chi^{2 \text { s }}$ [3] $=12.89-17.44, p$

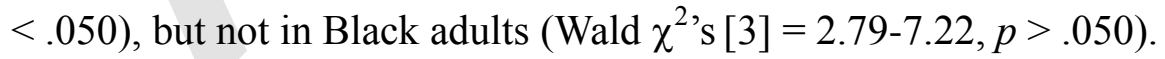

Conclusion: The lack of SES mobility differentiation on inflammation is an indication of diminished return for the most affluent class among Black participants. 
Keywords: Health disparities, Inflammation, Latent class analysis, Life course, Race/ ethnicity, Socioeconomic status (SES), Social mobility, USA

Acronyms:

$\mathbf{S E S}=$ Socioeconomic status; MIDUS $=$ Midlife in the United States; CRP $=$ C-reactive protein; IL-6 = interleukin-6; sICAM-1 = soluble intracellular adhesive molecule $1($ sICAM-1); $\mathbf{C V}=$ coefficient of variability; LCA $=$ latent class analysis; AIC = Akaike information criterion; $\mathbf{B I C}$ $=$ Bayesian information criterion; $\mathbf{a}-\mathbf{B I C}=$ sample size adjusted BIC; $\mathbf{B L R T}=$ bootstrapped likelihood ratio test. 
Persistent racial inequalities in health, especially between Whites and Blacks, have been a long-standing public health concern in the United States (1). A substantial proportion of racial disparities in health are explained by socioeconomic status (SES) differences between races (2). SES variation creates health disparities through complex pathways involving psychological and biological mediators (3). Inflammatory processes have been hypothesized to mediate the pathways through which SES links to the development and progression of chronic diseases, such as cardiovascular disease (4). However, findings regarding the interaction between SES and race/ ethnicity on affecting inflammatory burden are mixed. A study found consistent SESinflammation associations in both Black and White adults (5). However, other studies (6-8) found a less consistent association between SES and inflammation among Black compared to White adults.

Gaining more attention is understanding the role of life course SES and its association with inflammation $(4,6,9)$. Life course analysis of SES focuses on understanding the effect of accumulation of socioeconomic disadvantage on health, sensitive periods in which SES conditions might have a greater effect on health during the life course, and the impact of socioeconomic mobility on health (9-11). Previous studies have examined the association between accumulation of socioeconomic adversity across the life course $(4,6,9)$ and tested the influence of childhood as a sensitive period for the inflammatory burden in adulthood (12). However, only few studies that have examined the linkage between SES mobility and inflammation across adulthood. Thus, examining the association between SES mobility, race/ ethnicity, and inflammation is important to better understand the physiological pathways through which social factor impacts health in different racial groups. 


\section{The Lack of Subjective Measures in SES Mobility Research}

Previous studies of SES mobility have used comparison of a single or composite score of objective childhood SES (i.e. parental education level) to a single or composite score of objective adult SES (i.e., individual's education level). However, past studies have not considered the role of subjective SES. Subjective SES refers to individual's appraisal regarding social status and ability to access resources. The majority of individuals refer to their financial situation when considering their subjective SES (13). Thus, in this study we used multiple indicators of subjective financial condition and strains across the life course to asses one's subjective SES.

Studies have shown consistent findings that subjective SES is a unique construct, independent of objective SES, on its ability to predict health (13-16). Studies have also shown that subjective SES is significantly associated with multiple mediators of SES-health association, such as stress, perceived control, and diurnal cortisol $(14,17,18)$. It is important to understand the interconnectedness between objective and subjective SES across the life course on forming one's SES mobility. Furthermore, multidimensionality of SES measures is critical to examine SES mobility among White and Black adults. For example, compared to Whites, Blacks have lower levels of income across different levels of education (19). On the other hand, Blacks, in general, have shown higher subjective SES compared to Whites (20). Thus, Whites and Blacks may have different patterns of SES mobility when both objective and subjective SES measures are being used.

\section{The Association between SES Mobility and Health among White and Black Adults}

Studies have shown Black-White differences in terms of the relationship between SES mobility and health $(21,22)$. There are several theories that might explain how SES mobility affects health differently between Black and White. The minority poverty hypothesis posits that 
Blacks who experience constant socioeconomic adversity across their life course would have worse health outcomes compared to Whites with similar socioeconomic conditions due to a double jeopardy of socioeconomic deprivation and racial discrimination, $(21,23)$. Similarly, the diminishing return hypothesis specifies that Blacks with constantly high levels of SES across their life course would have fewer health benefits compared to their White counterparts, also due to racial discrimination (21). Finally, the skin-deep resilience hypothesis posits that for Blacks to achieve socioeconomic mobility amid great stressors due to childhood socioeconomic deprivation and racial discrimination may cost them physiologically due to physical wear and tear (24).

It is unclear how socioeconomic mobility across the life course relates to inflammation. Life course analysis on early life adversity provides a clue that childhood may be a sensitive period for the development of inflammatory burden across adulthood (12). Studies have found that childhood SES is associated with markers of inflammation across adulthood $(25,26)$. A study found that those who experience upward mobility show higher levels of inflammatory markers compared to those in the stable high SES (27), further support the assertion that childhood is a sensitive period for the development of inflammatory burden in adulthood. However, other studies have shown that adult SES was more strongly related to inflammation in adulthood $(7,9)$. Less is known regarding the association between SES mobility and markers of inflammation among White and Black adults.

In summary, the goal of this study is twofold: (a) to model socioeconomic mobility across the life course among White and Black adults based on objective and subjective indicators of SES using latent class analysis (LCA), and (b) to examine the association between SES mobility and inflammation markers among White and Black adults. Latent class analysis (LCA) is a 
suitable approach on modeling heterogeneity of SES mobility based on multiple indicators of objective and subjective SES by providing an intuitive and parsimonious solution (28).

\section{Methods}

\section{Participants and Procedures}

This study utilized data from the Midlife in the United States (MIDUS) study (midus.wisc.edu). The first wave of MIDUS study was conducted from 1995 to 1996, followed by the second wave in 2004. In 2011, the MIDUS Refresher study was conducted to investigate the impact of the Great Recession in the late 2000s on health and to refresh and expand the MIDUS study by recruiting a new set of participants (29). Recruitment of participants, data collection process, and study protocols in MIDUS Refresher were similar to the main study of MIDUS. MIDUS Refresher study recruited 3,577 new participants (response rate $=59 \%$ ) through random dial digit who completed baseline telephone interview. Among them, 2,600 participants $(73 \%$ of the phone interview participants) also completed self-administered questionnaires (SAQ). The main sample of MIDUS Refreshers comprised of $82.5 \%$ White and 9.7\% Black participants. In order to oversample the Black participants, a supplemental sample was drawn from Milwaukee County, WI. The supplemental sample included 508 participants who completed in-person interviews (response rate $=47.7 \%$ ). Among them, 299 participants (59\% of the in-person interview participants) also completed the SAQ. The Milwaukee

supplemental sample comprised of 3.9\% White and $90.9 \%$ Black participants. Those who completed both the baseline survey and SAQ were eligible to participate in the biomarker assessment. 
The biomarker assessment of the MIDUS Refresher $(n=863)$ was conducted in 2013 to 2016. Participants were invited to stay overnight at one of the three regional clinical research units, whichever imposed the least travel burden. Data for this analysis were from 750 biomarkers study participants (mean [SD] age $=50.84$ [13.41]; 52.1\% were female; 86.4\% MIDUS Refresher main sample, 13.6\% MIDUS Refresher Milwaukee supplemental survey) who self-identified as non-Hispanic White (592; 99\% from the main sample) and non-Hispanic Black participants $(158 ; 34.8 \%$ from the main sample). Participants signed an informed consent to participate in both the baseline survey and the biomarker study. Sociodemographic characteristics of the participants were presented in Table 1.

\section{Measures}

\section{Life Course SES}

There are eight measures used as the indicators of life course SES, including: (1) father's (or mother if data was missing) highest level of education $(1=<$ high school, $2=$ high school/ GED and above); (2) whether family of origin received welfare ( 1 = yes, $2=$ never); and (3) perception of financial level growing up $(1=\mathrm{a}$ lot/ somewhat/ a little worse off than average families; 2 = same/ a little/ somewhat/ a lot better off than average families); (4) participants' level of education ( 1 = high school/GED or less, 2 = some college or above); (5) household-sized adjusted income to poverty ratio $(1=$ less than $150 \%$, equal to or more than $150 \%)$; $(6)$ perception of current financial level $(0=$ worst, $10=$ best; recoded into $1=$ responded $0-5$ on the original scale, $2=$ responded $6-10$ on the original scale); (7) perception of the availability of money $(1=$ not enough money, 2 = enough money or more money than you need), and (8) perception of hardship on paying bills $(1=$ very/ somewhat difficult, $2=$ not very difficult/ not at all difficult). 
Parental education and welfare status are considered as objective indicators of childhood SES, while perceived financial level growing up is considered as the subjective indicator. Education and income to poverty ratio is considered as the objective indicators of adult SES and the rest of adult SES measures are considered as the subjective indicators of adult SES. This set of life course SES measures has been previously used as a composite measure of childhood SES, adult SES, or life course SES and was a significant predictor of various health outcomes across adulthood, including daily stress and daily negative affect (29), allostatic load (30), diabetes (31), and reported chronic disease (32).

\section{Markers of Inflammation}

Three markers of low-grade inflammation were used in this analysis, C-reactive protein (CRP), interleukin 6 (IL-6), and soluble intracellular adhesive molecule 1 (sICAM-1). Blood CRP was measured using a particle-enhanced immunonephelometric assay (BNII nephelometer,

Dade Behring Inc., Deerfield, IL). The assay range is $0.164-800 \mathrm{ug} / \mathrm{mL}$, intra-assay coefficients of variability (CVs) range from 2.3 to $4.4 \%$ and inter-assay CVs range from 4.72 to $5.16 \%$. Blood serum IL-6 was measured using ultra-sensitive ELISA (R\&D Systems, Minneapolis, MN). The assay range is $0.156-10 \mathrm{pg} / \mathrm{mL}$, intra-assay CV was $3.73 \%$ and inter-assay CV was $15.66 \%$. sICAM-1 was measured by sandwich ELISA Quantikine ${ }^{\circledR}$ kit (R\&D Systems, Minneapolis, $\mathrm{MN}$ ). The assay range is $31-1000 \mathrm{ng} / \mathrm{mL}$, intra-assay CVs range from 3.7 to $5.2 \%$ and inter-assay CVs range from 7.49 to $8.16 \%$. IL-6 was assayed in the MIDUS Biocore Laboratory at the University of Wisconsin, Madison, WI. CRP, and sICAM-1 were assayed at the Laboratory for Clinical Biochemistry Research at the University of Vermont, Burlington, VT. Natural Logtransformed data for CRP, IL-6, and sICAM-1 were used for further analysis. 


\section{Statistical Analysis}

Latent class analysis (LCA) was used to identify unique groups of SES mobility based on eight observed, binary indicators of life course SES (Table 1). LCA progressed in two steps. The first step identified and described latent classes of life course SES using LCA. The second step assessed whether class membership was associated with inflammation markers. Selection of the optimally fitting model was based on model fit statistics and selection criteria, parsimony principle, as well as theoretical interpretability. Extensive explanations about technical aspects of model selection in LCA have been disseminated somewhere else (33). Model with 1 to 6 classes were considered (using 1,000 sets of random starting values) before selecting the best fitting model. All models were estimated using PROC LCA on SAS version 9.4 (33).

The second phase of the analysis used the latent classes of SES mobility to predict inflammation markers, using the $\mathrm{BCH}$ approach (34). The $\mathrm{BCH}$ approach uses posterior probabilities of class membership based on the latent class model to compute a special weighting variable. The mean of outcome variables for each class was then calculated based on this weighting variable. Finally, pairwise comparisons of the expected values of the distal outcomes were conducted using Wald tests. To compensate for multiple comparisons, Bonferroni correction was applied. Distal outcome analysis was conducted using LCA_Distal_BCH SAS Macro (35).

\section{Results}

We initially analyzed data by combining both White and Black participants $(\mathrm{N}=750)$ to test whether latent classes of life course SES have equal meaning across racial groups. Information regarding model fit statistics and selection criteria are shown in Table 2. The 4-class 
model showed the best fit, indicated by lower a-BIC, and it was the last class with a significant BLRT (indicated that the 5-class model did not have significantly better model fit compared to the 4-class model). Measurement invariance test of the 4-class model based on race showed that there were severe measurement differences between White and Black $\chi^{2}(32)=65.16, p<.001$, indicating that latent class structures of life course SES between White and Black participants were different. Further analysis was conducted by developing separate latent class models of SES mobility separately for White and Black participants. The results from the separate LCA analyses are presented below.

\section{SES Mobility Among White Participants}

Table 2 provides model fit statistics and selection criteria for the White sample. Model with 1-6 classes were considered. The a-BIC was reduced for the 4-class model; however, the AIC and BIC for the 4-class model were slightly higher than other class models. The BLRT was not significant for the 6-class model, suggested the 5-class model as a favored model. Based on the model selection criteria, the best fitting model for White participants was between 4-class or 5-class model. Upon closer inspection, the 5-class model characterized by two redundant classes that were grouped into one class in the 4-class model. Thus, the 4-model was selected as the best fit model for theoretical explanation and further analysis.

Information regarding latent class membership probabilities and item-response probabilities for the 4-class model of life course SES among White are presented in Table 3. Class 1 (1.95\% prevalence) was characterized by low levels of SES, both objective and subjective, across the life course. This class was labeled as the Always Low class. Class 2 (18.4\%) was characterized by low objective and subjective childhood SES, high education, and high objective and subjective adult SES. Class 2 was identified as Upwardly Mobile. Class 3 
(27.74\%) was named Subjectively Downward class, as it was characterized by high objective and subjective childhood SES, high education, high objective adult SES (i.e., income to poverty ratio), but low across all indicators of subjective adult SES. The last class, class 4 (52.17\%), was characterized by high levels of SES, both objective and subjective, across the life course. Class 4 was labeled Always High.

\section{SES Mobility and Inflammation Markers Among White Participants}

The omnibus test showed that expected means of $\log$ IL-6 $\left(\chi^{2}[3]=17.44, p<.001\right), \log$ $\operatorname{CRP}\left(\chi^{2}[3]=15.08, p<.010\right)$, and $\log \operatorname{sICAM}-1\left(\chi^{2}[3]=12.89, p<.010\right)$ differed significantly by class membership. The expected mean levels of log IL-6 and log CRP for each class are presented in the top part of Table 3. Figure 1 showed that the expected mean of log IL-6 for the Always Low class was significantly lower than the Always High $\left(\chi^{2}[1]=15.52, p<.050\right)$ and Subjectively Downward $\left(\chi^{2}[1]=9.72, p<.050\right)$. The expected mean of $\log$ CRP for the Always Low class was significantly lower than the Always High class $\left(\chi^{2}[1]=9.77, p<.050\right.$; Figure 1$)$. Finally, the expected mean of $\log$ sICAM-1 for the Always Low class was significantly lower than the Always High class $\left(\chi^{2}[1]=7.61, p<.050 ;\right.$ Figure 1$)$

\section{SES Mobility Among Black Participants}

Table 3 details information regarding model fit statistics and selection criteria for the Black sample. Model with 1 to 6 classes were considered. The 4-class model showed the lowest level of AIC and a-BIC, but not the BIC. BLRT of the 4-class model was marginally significant $(p<.1)$, indicating that the 3-class model was preferable. Entropy for the larger models ranged from .80 to .84 . Based on the model selection criteria, the best fitting model for Black participants was between 3-class or 4-class model. Closer inspection indicated that an additional 
class in the 4-profile model show a non-repetitive, meaningful, and interpretable class. Thus, the 4-model was selected as the best fit model for theoretical explanation and further analysis.

Latent class membership probabilities and item-response probabilities for the 4-class model of life course SES among Black sample are shown in the bottom part of Table 4. Class 1 (32.97\%) was labeled Always Low; it characterized by low levels of objective and subjective SES across the life course. Class 2 (35.84\%) was characterized by high objective and subjective childhood SES, high education, but low objective and subjective adult SES. This class was named Downwardly Mobile. Class 3 (6.48\%) was labeled Subjectively Always High, characterized by low objective childhood SES, low objective adult SES, high subjective childhood SES, and high subjective adult SES. Class 4 (24.71\%) was characterized by high objective childhood SES, high objective adult SES, high subjective adult SES, but low subjective childhood SES. This class was labeled Objectively Always High.

\section{SES Mobility and Inflammation Markers Among Black Participants}

The expected mean of $\log \operatorname{IL}-6\left(\chi^{2}[3]=4.38, p=.22\right)$ and $\log \operatorname{sICAM}-1\left(\chi^{2}[3]=2.79, p\right.$ $=.42)$ did not significantly differ, while the expected mean of $\log \operatorname{CRP}\left(\chi^{2}[3]=7.22, p=.065\right)$ marginally differed by SES mobility. Pairwise comparisons indicated that there was no significant different expected mean log IL-6, log CRP, and log sICAM-1 between classes (Figure 2).

\section{Discussion}

This study is among the first that utilizes latent class analysis to examine heterogeneity of SES mobility using both objective and subjective indicators of SES among White and Black adults in the United States. Furthermore, this article was intended to investigate the association 
between SES mobility and inflammation markers, including IL-6, CRP, and sICAM-1. We found that the 4-class solution was the best fitting model for both White and Black participants. However, the class structure of SES mobility was different between White and Black participants. Among Black participants, class membership was not a significant predictor of inflammation. On the other hand, class membership among White participants was significantly associated with all markers of inflammation.

Among White participants, we found two classes of stable life course SES (Always High and Always Low) and two classes that are characterized by mobility (Upwardly Mobile and Subjectively Downward). The overwhelming prevalence of stable high class among White participants represents the general characteristics of MIDUS study participants that include mostly individuals from middle to higher levels of SES. Except for the Subjectively Downward, the three other classes are similar to findings from previous studies on SES mobility using a traditional comparison of childhood SES and adult SES approach. The Subjectively Downward is a unique SES mobility class that comes up as we combined both subjective and objective indicators of SES. Given that MIDUS Refresher was conducted post the Great Recession, the low probabilities in all subjective adult SES despite high probability for income in this class may be the indication of how recession affects some White participants. Studies have shown that when using objective SES, minorities are disproportionately experienced losses compared to Whites (36). The Subjectively Downward class may be an indication that among some White participants, the impact of the Great Recession on subjective SES is more salient.

Among Black participants, we found two similar characteristics of SES mobility as in previous studies (Always Low and Downwardly Mobile) and two novel characteristics of mobility (Subjectively Always High and Objectively Always High). Only one class among four 
classes in Black (Objectively Always High) that has high item-response probability for incometo-poverty line ratio, while there were three classes among White participants (Upwardly Mobile, Subjectively Downward, and Always High). This result corroborates previous findings that Blacks have lower levels of material resources compared to White across all levels of SES (19). The lower levels of material resources among Blacks may also be a reason for the lack of an upwardly mobile class among Black participants. Given that the majority of Black participants in this study were drawn from Milwaukee County, the lack of pattern of upward mobility may be unique to this sample.

The Downwardly Mobile class among Black participants was characterized by low objective and subjective adult SES despite high levels of objective and subjective childhood SES and education. In other studies, downward mobility is usually attributed to low levels of education despite the high level of childhood SES $(9,37)$. For some Black participants, the experience of college education may not guarantee higher levels of adult SES, both objectively and subjectively. Middle class Blacks are especially vulnerable to downward mobility because despite achieving higher levels of education, they lag behind Whites on accumulating wealth such as owning home (38) and they are more vulnerable to the impact of the economic downturn $(36,38,39)$.

Despite low in prevalence, the Subjectively Always High is an interesting class among Black participants, given that it was characterized by high subjective SES across the life course despite material deprivation in childhood and adulthood. One possible explanation regarding the Subjectively Always High class is the optimism and religiosity among Black participants. As shown in a study (40), optimism among Blacks is not differentiated by SES. Furthermore, optimism, but not pessimism, among Blacks is rooted in their tendency to be spiritual, especially 
among the older cohort (41). Thus, the Subjectively Always High class may represent Black participants that utilize spirituality and optimism to deal with material deprivation. On the other hand, the Objectively Always High class gives an indication that among Black participants, even the most affluent group experience a certain type of hardship across their life course. The perceived low childhood SES despite high objective childhood SES in this class may be associated with the perception of socioeconomic hardship that is experienced by Black participants in general due to racism and discrimination, regardless of the level of SES.

Class membership among White participants was consistently associated with inflammation makers. As expected, constant objective and subjective socioeconomic adversity across the life course is associated with higher levels of inflammatory burden. On the other hand, constant high objective and subjective SES across the life course was associated with lower levels of inflammation. We found that levels of CRP, IL-6, and sICAM-1 of the most disadvantaged class were significantly higher than the most privileged class. These results corroborate findings from previous studies on the influence of SES mobility on the same inflammatory markers $(9,26)$.

One interesting finding from the analysis among White participants was the lack of differences in terms of inflammatory burden between the Upwardly Mobile and Subjectively Downward classes. The expected means of inflammation markers for the Upwardly Mobile were not significantly different from the Subjectively Downward. Although low childhood SES may leave a scar in the physiological functioning for the Upwardly Mobile class, the better psychosocial mediators may play as protective factors. Future studies should prioritize directly testing whether there is a chain of risks from life course SES adversity, psychosocial factors, and inflammatory burden. In addition, the expected means of inflammation markers for both the 
Upwardly Mobile and Subjectively Downward were not significantly different from the group means among White participants, except for the sICAM-1. The Subjectively Downward class showed an elevated level of sICAM-1 compared to the overall mean among White participants. The similar finding regarding downward mobility and elevated sICAM-1 was also found by Loucks et al. (9). sICAM-1 may be sensitive to current levels of SES, including both objective and subjective SES. A better understanding of the association between SES, psychosocial mediators, and sICAM-1 would have important public health implication. Previous study has shown that elevated sICAM-1 is associated with the development of cardiovascular disease (42).

The fact that the biological indicators were not differentiated based on SES mobility among Black participants may provide an indication of support for the diminishing return hypothesis. It is possible that the socioeconomic benefit among the most affluent Blacks diminished due to a constant experience of daily discrimination. Racial discrimination is rampant among Blacks, regardless of SES, and associated with worse health outcome (43). The lack of health benefits among the most affluent Black participants may be due to a better understanding of social injustice and racial discrimination among them associated with better education and SES in general (21). This realization of social injustice among the more affluent group in Black may be associated with higher levels of stress that undermine the health benefit of being in higher levels of SES. A laboratory study found that higher perceived discrimination among Blacks was associated with higher inflammatory response, especially among those with stronger racial identity (44). Future studies should consider testing the interaction between SES mobility, discrimination, and inflammation among White and Black adults, especially in a natural setting. 


\section{Strength and Limitations}

The present study applied a novel statistical analysis to examine SES mobility using both objective and subjective indicators of SES across the life course. The LCA provides an intuitive and parsimonious description of the heterogeneity of SES mobility across the life course. This study provides a novel knowledge regarding the different structure of SES mobility between White and Black adults and racial differences related to how SES mobility associated with inflammation markers. The results from this study added to the lack of knowledge regarding the association between SES mobility and biological mediator of health.

In light of these strengths, there are several limitations of the current study. First, life course SES data were collected using a self-report retrospective method that may lead to measurement imprecision. Future replication is needed using prospective data to test the reliability of the SES mobility classes among White and Black participants. Second, this data was collected right after the Great Recession at the end of the 2000s. The classes of SES mobility that we found in this study may be unique due to the impact of the economic downturn. Replication using data from a different wave of MIDUS study will be an interesting way to test the reliability of the classes. Furthermore, most of Black participants in this study were drawn from Milwaukee County in contrast to White participants who were drawn from a national sample. Milwaukee is known for its high levels of racial segregation (45). The lack of SES

mobility differentiation on inflammatory burden among Black participants may be due to a unique experience of the Milwaukee participants in this study. Future research should further examine the diminished return hypothesis using a more representative of the national Black population. 
In addition to that, the low number of Black participants in this study may have resulted in insufficient power to detect the significant association between class membership and the outcomes. We conducted power analysis to further examine that possibility. Although there is no clear information regarding the effect size of the association between SES mobility and inflammation among Black, we found that in general the effect size between SES and inflammation is ranging from small to medium $(.150-.300)(6,46,47)$. We found that the required sample size to detect the effect $(\alpha=.050,1-\beta=.800)$ is ranging from 143 to 571 . Although the Black sample size is in the lower end of the required sample size, our results align with those previous studies with larger sample sizes, which all demonstrated consistent results of a lack of significant association between SES and inflammation markers, especially IL-6 and CRP (6-8).

The distal outcome analyses did not control for age, sex, and BMI. It is possible to analyze the interaction between latent classes of SES mobility and age or sex and their associations with markers of inflammation by conducting multiple groups distal outcome analysis. However, given that some classes have a rather small prevalence and given that this study included rather a smaller sample size, a multiple group distal outcome analysis would be underpowered. Future studies should prioritize analyzing the modifying role of age and sex on the association between SES mobility and inflammation markers among White and Black participants. Our additional analysis indicated that measurement invariance assumption based on sex among Black participants was violated $\left(\chi^{2}[32]=53.98, p<.010\right)$, but not among White participants. This may indicate differences in the heterogeneity of SES mobility between male and female Black participants that may lead to different association between SES mobility and inflammation based on sex among Black participants. As previously shown in another study (6), 
there are sex differences in the association between SES and CRP and IL-6 between Black males and females, but not among White participants. While this may rise question regarding the validity of SES mobility classes among Black participants, our findings reflect the general pattern of SES mobility among overall Black participants. The consistency with previous findings (6-8) strongly suggest that there is no differentiation of CRP and IL-6 based on SES among Blacks. Nonetheless, the intersectionality between sex and SES among Blacks should be a priority for future studies in understanding disparities in inflammation. Finally, there are several limitations regarding the life course SES measures used in this analysis. Although we divided SES into objective and subjective measures, the objective indicators of SES were still based on self-report which may decrease the objectivity of the measures. Furthermore, respondents may vary in the referent they use in making subjective ratings.

In summary, the current study adds to the knowledge of how SES mobility, using both objective and subjective indicators, is associated with inflammation markers. Using LCA, we showed that White and Black participants have different class structure of SES mobility. In addition, we found that class membership of SES mobility is associated with inflammatory burden among White participants, but not among Black participants. The lack of SES mobility differentiation on inflammation may be an indication of diminished return for the most affluent group among Black participants. 


\section{References}

1. Williams DR, Mohammed SA, Leavell J, Collins C. Race, socioeconomic status, and health: complexities, ongoing challenges, and research opportunities. Annals of the New York Academy of Sciences. 2010;1186:69-101.

2. Hayward MD, Miles TP, Crimmins EM, Yang Y. The significance of socioeconomic status in explaining the racial gap in chronic health conditions. American sociological review. 2000:910-30.

3. Matthews KA, Gallo LC. Psychological perspectives on pathways linking socioeconomic status and physical health. Annual review of psychology. 2011;62:501-30.

4. Pollitt RA, Kaufman JS, Rose KM, Diez-Roux AV, Zeng D, Heiss G. Cumulative life course and adult socioeconomic status and markers of inflammation in adulthood. Journal of epidemiology and community health. 2008;62:484-91.

5. Koster A, Bosma H, Penninx BW, Newman AB, Harris TB, van Eijk JT, Kempen GI, Simonsick EM, Johnson KC, Rooks RN, Ayonayon HN, Rubin SM, Kritchevsky SB. Association of inflammatory markers with socioeconomic status. The journals of gerontology Series A, Biological sciences and medical sciences. 2006;61:284-90.

6. Gruenewald TL, Cohen S, Matthews KA, Tracy R, Seeman TE. Association of socioeconomic status with inflammation markers in black and white men and women in the Coronary Artery Risk Development in Young Adults (CARDIA) study. Social science \& medicine (1982). 2009;69:451-9.

7. Pollitt RA, Kaufman JS, Rose KM, Diez-Roux AV, Zeng D, Heiss G. Early-life and adult socioeconomic status and inflammatory risk markers in adulthood. European journal of epidemiology. 2007;22:55-66. 
8. Ranjit N, Diez-Roux AV, Shea S, Cushman M, Ni H, Seeman T. Socioeconomic position, race/ethnicity, and inflammation in the multi-ethnic study of atherosclerosis. Circulation. 2007;116:2383-90.

9. Loucks EB, Pilote L, Lynch JW, Richard H, Almeida ND, Benjamin EJ, Murabito JM. Life course socioeconomic position is associated with inflammatory markers: the Framingham Offspring Study. Social science \& medicine (1982). 2010;71:187-95.

10. Ben-Shlomo Y, Kuh D. A life course approach to chronic disease epidemiology: conceptual models, empirical challenges and interdisciplinary perspectives. International journal of epidemiology. 2002;31:285-93.

11. Kuh D, Ben-Shlomo Y, Lynch J, Hallqvist J, Power C. Life course epidemiology. Journal of epidemiology and community health. 2003;57:778.

12. Miller GE, Chen E, Fok AK, Walker H, Lim A, Nicholls EF, Cole S, Kobor MS. Low early-life social class leaves a biological residue manifested by decreased glucocorticoid and increased proinflammatory signaling. Proceedings of the National Academy of Sciences of the United States of America. 2009;106:14716-21.

13. Singh-Manoux A, Marmot MG, Adler NE. Does subjective social status predict health and change in health status better than objective status? Psychosomatic medicine. $2005 ; 67: 855-61$.

14. Adler NE, Epel ES, Castellazzo G, Ickovics JR. Relationship of subjective and objective social status with psychological and physiological functioning: preliminary data in healthy white women. Health Psychol. 2000;19:586-92.

15. Ostrove JM, Adler NE, Kuppermann M, Washington AE. Objective and subjective assessments of socioeconomic status and their relationship to self-rated health in an ethnically diverse sample of pregnant women. Health Psychol. 2000;19:613-8. 
16. Singh-Manoux A, Adler NE, Marmot MG. Subjective social status: its determinants and its association with measures of ill-health in the Whitehall II study. Social science \& medicine (1982). 2003;56:1321-33.

17. Ghaed SG, Gallo LC. Subjective social status, objective socioeconomic status, and cardiovascular risk in women. Health Psychol. 2007;26:668-74.

18. Wright CE, Steptoe A. Subjective socioeconomic position, gender and cortisol responses to waking in an elderly population. Psychoneuroendocrinology. 2005;30:582-90.

19. Williams DR, Sternthal M. Understanding racial-ethnic disparities in health: sociological contributions. Journal of health and social behavior. 2010;51 Suppl:S15-27.

20. Wolff LS, Acevedo-Garcia D, Subramanian SV, Weber D, Kawachi I. Subjective social status, a new measure in health disparities research: do race/ethnicity and choice of referent group matter? Journal of health psychology. 2010;15:560-74.

21. Farmer MM, Ferraro KF. Are racial disparities in health conditional on socioeconomic status? Social science \& medicine (1982). 2005;60:191-204.

22. Miller GE, Cohen S, Janicki-Deverts D, Brody GH, Chen E. Viral challenge reveals further evidence of skin-deep resilience in African Americans from disadvantaged backgrounds. Health Psychol. 2016;35:1225-34.

23. Willie CV. The caste and class controversy on race and poverty: Round two of the Willie/Wilson debate: Rowman \& Littlefield; 1989.

24. Brody GH, Yu T, Chen E, Miller GE, Kogan SM, Beach SR. Is resilience only skin deep?: rural African Americans' socioeconomic status-related risk and competence in preadolescence and psychological adjustment and allostatic load at age 19. Psychological science. 2013;24:1285-93. 
25. Carroll JE, Cohen S, Marsland AL. Early childhood socioeconomic status is associated with circulating interleukin-6 among mid-life adults. Brain, behavior, and immunity. 2011;25:1468-74.

26. Stringhini S, Batty GD, Bovet P, Shipley MJ, Marmot MG, Kumari M, Tabak AG, Kivimaki M. Association of lifecourse socioeconomic status with chronic inflammation and type 2 diabetes risk: the Whitehall II prospective cohort study. PLoS medicine. 2013;10:e1001479.

27. Castagne R, Delpierre C, Kelly-Irving M, Campanella G, Guida F, Krogh V, Palli D, Panico S, Sacerdote C, Tumino R, Kyrtopoulos S, Hosnijeh FS, Lang T, Vermeulen R, Vineis P, Stringhini S, Chadeau-Hyam M. A life course approach to explore the biological embedding of socioeconomic position and social mobility through circulating inflammatory markers. Scientific reports. 2016;6:25170.

28. Fosco GM, Bray BC. Profiles of cognitive appraisals and triangulation into interparental conflict: Implications for adolescent adjustment. Journal of family psychology : JFP : journal of the Division of Family Psychology of the American Psychological Association (Division 43). 2016;30:533-42.

29. Surachman A, Wardecker B, Chow SM, Almeida D. Life Course Socioeconomic Status, Daily Stressors, and Daily Well-Being: Examining Chain of Risk Models. The journals of gerontology Series B, Psychological sciences and social sciences. 2019;74:126-35.

30. Gruenewald TL, Karlamangla AS, Hu P, Stein-Merkin S, Crandall C, Koretz B, Seeman TE. History of socioeconomic disadvantage and allostatic load in later life. Social science \& medicine (1982). 2012;74:75-83. 
31. Tsenkova V, Pudrovska T, Karlamangla A. Childhood socioeconomic disadvantage and prediabetes and diabetes in later life: a study of biopsychosocial pathways. Psychosomatic medicine. 2014;76:622-8.

32. Ferraro KF, Schafer MH, Wilkinson LR. Childhood Disadvantage and Health Problems in Middle and Later Life: Early Imprints on Physical Health? American sociological review. 2016;81:107-33.

33. Lanza ST, Collins LM, Lemmon DR, Schafer JL. PROC LCA: A SAS Procedure for Latent Class Analysis. Structural equation modeling : a multidisciplinary journal. 2007;14:671-94.

34. Bakk Z, Vermunt JK. Robustness of stepwise latent class modeling with continuous distal outcomes. Structural Equation Modeling: A Multidisciplinary Journal. 2016;23:20-31.

35. Dziak JJ, Bray BC, Wagner AT. LCA_Distal_BCH SAS Macro Users' Guide (Version 1.1). The Methodology Center, University Park, PA, Penn State. 2017.

36. Hoynes H, Miller DL, Schaller J. Who suffers during recessions? Journal of Economic perspectives. 2012;26:27-48.

37. Luo Y, Waite LJ. The impact of childhood and adult SES on physical, mental, and cognitive well-being in later life. The journals of gerontology Series B, Psychological sciences and social sciences. 2005;60:S93-s101.

38. Hardaway CR, McLoyd VC. Escaping poverty and securing middle class status: how race and socioeconomic status shape mobility prospects for African Americans during the transition to adulthood. Journal of youth and adolescence. 2009;38:242-56.

39. McKernan S-M, Ratcliffe C, Steuerle E, Zhang S. Disparities in wealth accumulation and loss from the great recession and beyond. American Economic Review. 2014;104:240-44. 
40. Mattis JS, Fontenot DL, Hatcher-Kay CA. Religiosity, racism, and dispositional optimism among African Americans. Personality and Individual Differences. 2003;34:1025-38.

41. Mattis JS, Fontenot DL, Hatcher-Kay CA, Grayman NA, Beale RL. Religiosity, optimism, and pessimism among African Americans. Journal of Black Psychology. 2004;30:187-207.

42. Demerath E, Towne B, Blangero J, Siervogel RM. The relationship of soluble ICAM-1, VCAM-1, P-selectin and E-selectin to cardiovascular disease risk factors in healthy men and women. Annals of human biology. 2001;28:664-78.

43. Van Dyke ME, Vaccarino V, Dunbar SB, Pemu P, Gibbons GH, Quyyumi AA, Lewis TT. Socioeconomic status discrimination and C-reactive protein in African-American and White adults. Psychoneuroendocrinology. 2017;82:9-16.

44. Lucas T, Wegner R, Pierce J, Lumley MA, Laurent HK, Granger DA. Perceived discrimination, racial identity, and multisystem stress response to social evaluative threat among African American men and women. Psychosomatic medicine. 2017;79:293.

45. Ransome Y, Slopen N, Karlsson O, Williams DR. Elevated inflammation in association with alcohol abuse among Blacks but not Whites: results from the MIDUS biomarker study. Journal of behavioral medicine. 2018;41:374-84.

46. Muscatell KA, Brosso SN, Humphreys KL. Socioeconomic status and inflammation: a meta-analysis. Molecular Psychiatry. 2018.

47. Petersen KL, Marsland AL, Flory J, Votruba-Drzal E, Muldoon MF, Manuck SB. Community socioeconomic status is associated with circulating interleukin-6 and Creactive protein. Psychosomatic medicine. 2008;70:646-52. 
Figures

Figure 1. Class membership and inflammation markers among Whites; a = significantly different from the Always High $(p<.050), \mathrm{b}=$ significantly different from the Subjectively Downward $(p$ $<.050), \mathrm{c}=$ significantly different from the Upwardly Mobile $(p<.050)$. To compensate for multiple comparisons, Bonferroni correction was applied.

Figure 2. Class membership and inflammation markers among Blacks. No significant pairwise comparison found across all inflammation markers. 
Figure 1

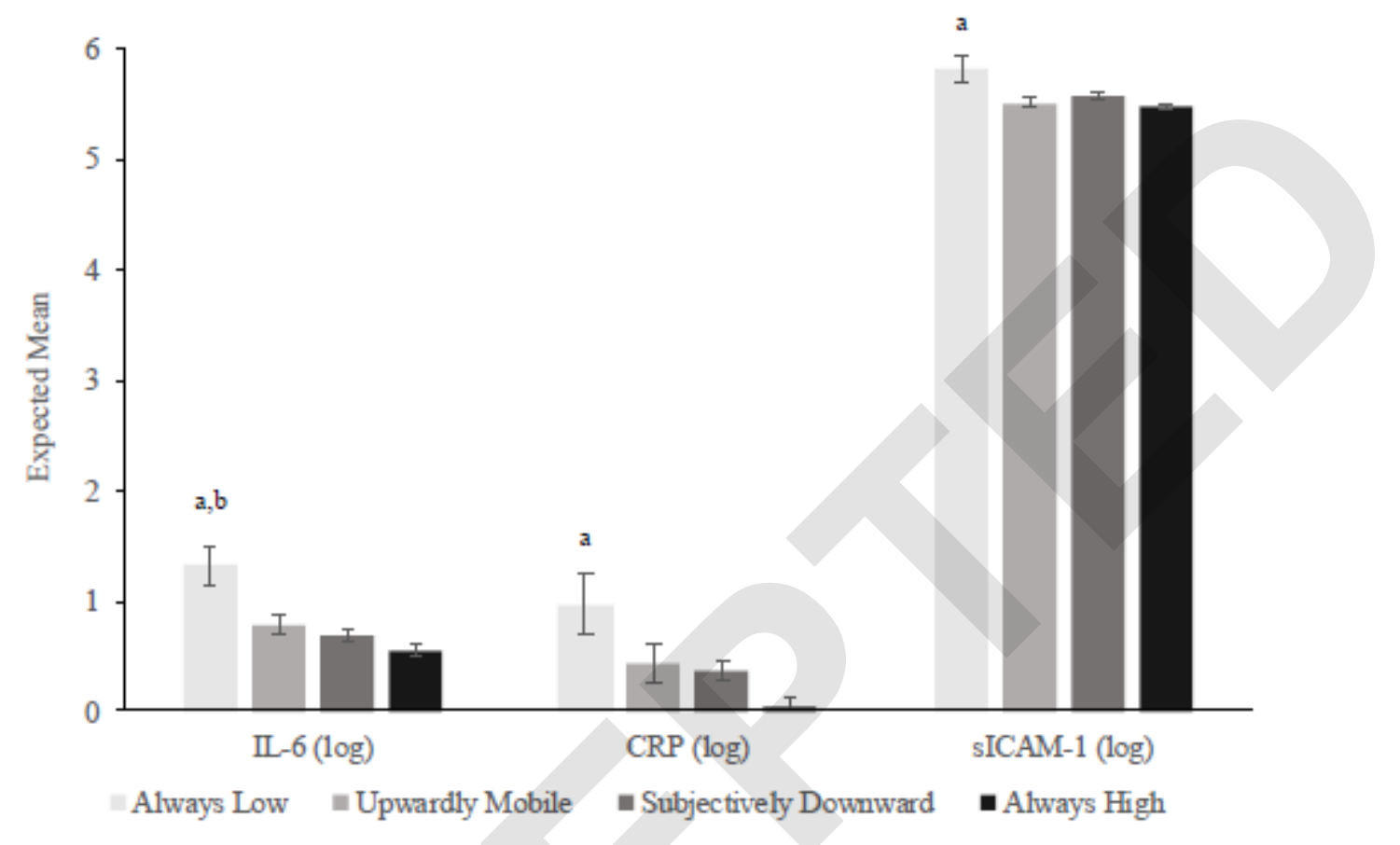


Figure 2

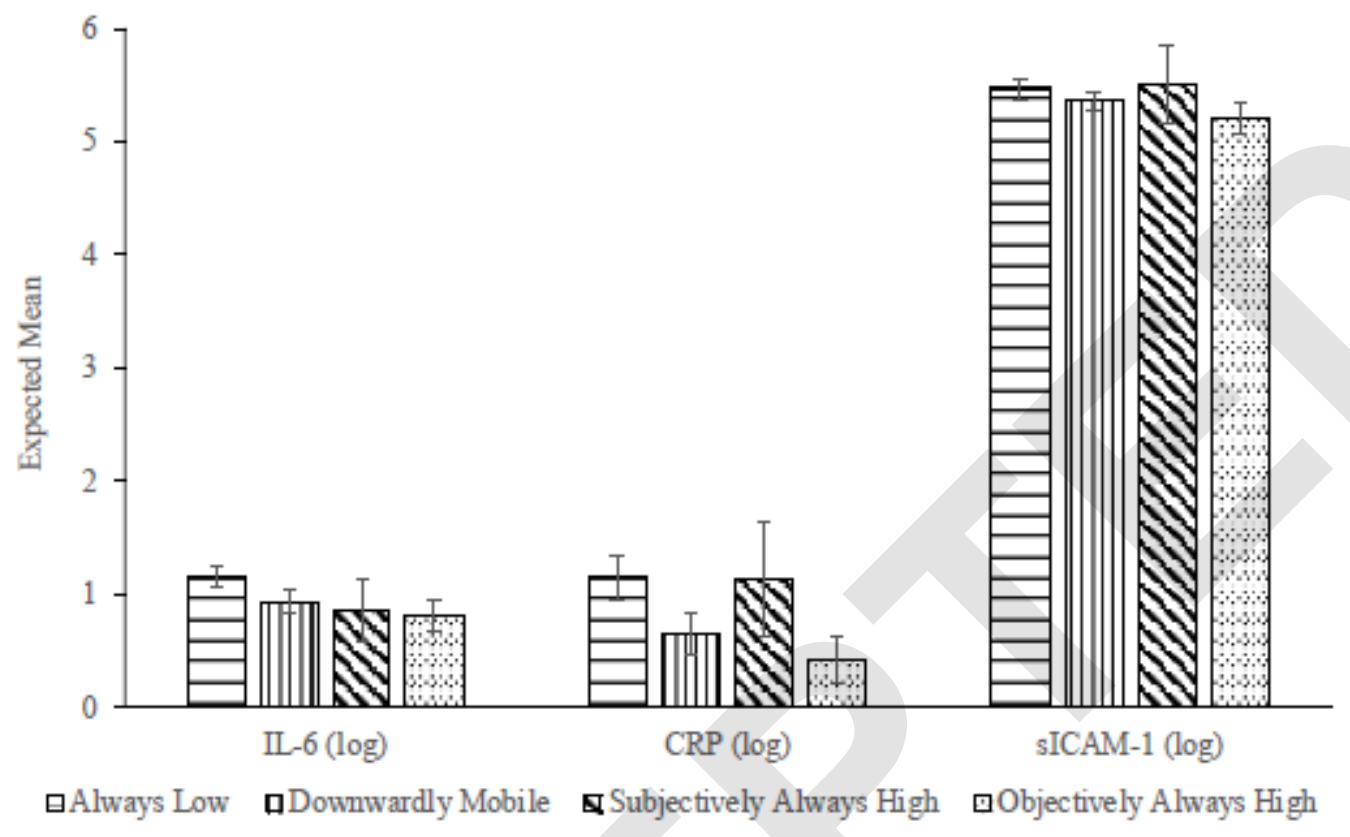


Table 1

Descriptive statistics for demographic characteristics, class indicators, and outcomes

\begin{tabular}{lll}
\hline Variable & \multicolumn{1}{l}{ Mean $\pm S D$ or $n(\%)$} & \\
\cline { 2 - 3 } Study & White $(n=592)$ & Black $(n=158)$ \\
MIDUS Main Survey & $586(99)$ & $55(34.8)$ \\
MIDUS Milwaukee Supplemental Sample & $6(1)$ & $103(65.2)$ \\
Demographic Characteristics & & \\
Female & $281(47.5)$ & $107(67.7)$ \\
Age & $52.5 \pm 13.4$ & $46.8 \pm 11.8$ \\
Indicators of Life Course SES & & \\
Childhood SES & & \\
$\quad$ Parent graduated from HS/GED or & $454(76.7)$ & $90(57.0)$ \\
$\quad$ higher & & $97(61.4)$ \\
$\quad$ Family of origin never received welfare & $549(92.7)$ & $102(64.6)$ \\
$\quad$ High financial level growing up & $403(68.1)$ & $105(66.5)$ \\
Adult SES & & $88(55.7)$ \\
$\quad$ Some college or higher & $513(86.7)$ & $60(38.0)$ \\
$\quad$ High income to poverty ratio & $513(86.7)$ & $67(42.4)$ \\
$\quad$ High current financial status & $411(69.4)$ & $52(32.9)$ \\
$\quad$ Enough money to fulfill basic needs & $454(76.7)$ & \\
$\quad$ Not difficult paying bills & $393(66.4)$ & $3.4 \pm 2.5$ \\
Inflammation & & $4.1 \pm 4.9$ \\
$\quad$ IL-6 (pg/mL) & $2.6 \pm 2.3$ & $252.6 \pm 147.5$ \\
$\quad$ CRP ( $\mu$ g/mL) & $2.6 \pm 5.2$ & \\
sICAM-1 (ng/mL) & $268.8 \pm 194.7$ & \\
\hline & & \\
\hline
\end{tabular}


Table 2

Model fit information for latent class analysis

\begin{tabular}{|c|c|c|c|c|c|c|c|}
\hline $\begin{array}{l}\text { No. of } \\
\text { classes }\end{array}$ & $\begin{array}{l}\text { Log- } \\
\text { likelihood }\end{array}$ & $\begin{array}{l}\text { No. of } \\
\text { parameters } \\
\text { estimated }\end{array}$ & AIC & $\mathrm{BIC}$ & $\mathrm{a}-\mathrm{BIC}$ & Entropy & BLRT \\
\hline \multicolumn{8}{|c|}{ White and Black combined $(n=750)$} \\
\hline 1 & -3309.38 & 8 & 1201.57 & 1238.53 & 1213.12 & - & - \\
\hline 2 & -2889.25 & 17 & 379.31 & 457.85 & 403.87 & .85 & $p<.010$ \\
\hline 3 & -2852.65 & 26 & 324.10 & 444.23 & 361.67 & .82 & $p<.010$ \\
\hline 4 & -2823.85 & 35 & 284.51 & 446.21 & 335.07 & .68 & $p<.010$ \\
\hline 5 & -2808.45 & 44 & 271.72 & 475.00 & 335.29 & .71 & $p<.050$ \\
\hline 6 & -2797.51 & 53 & 267.82 & 512.69 & 344.39 & .74 & $p>.050$ \\
\hline \multicolumn{8}{|c|}{ White $(n=592)$} \\
\hline 1 & -2300.80 & 8 & 821.49 & 856.56 & 831.16 & & - \\
\hline 2 & -2033.14 & 17 & 304.16 & 378.68 & 324.71 & .87 & $p<.010$ \\
\hline 3 & -2000.96 & 26 & 257.79 & 371.76 & 289.22 & .74 & $p<.010$ \\
\hline 4 & -1979.41 & 35 & 232.71 & 386.13 & 275.02 & .78 & $p<.010$ \\
\hline 5 & -1966.96 & 44 & 225.81 & 418.68 & 279.00 & .77 & $p<.050$ \\
\hline 6 & -1958.84 & 53 & 227.57 & 459.89 & 291.63 & .84 & $p>.050$ \\
\hline \multicolumn{8}{|c|}{ Black $(n=158)$} \\
\hline 1 & -819.25 & 8 & 358.62 & 383.12 & 357.80 & - & - \\
\hline 2 & -753.58 & 17 & 245.29 & 297.35 & 243.54 & .84 & $p<.010$ \\
\hline 3 & -739.41 & 26 & 234.94 & 314.57 & 232.26 & .82 & $p<.050$ \\
\hline 4 & -728.34 & 35 & 230.80 & 337.99 & 227.20 & .81 & $p>.050$ \\
\hline 5 & -721.07 & 44 & 234.26 & 369.01 & 229.73 & .80 & $p>.050$ \\
\hline 6 & -713.87 & 53 & 237.85 & 400.17 & 232.40 & .84 & $p>.050$ \\
\hline
\end{tabular}

Note: Dashes indicate criterion was not applicable; boldface type indicates selected

model. AIC $=$ Akaike information criterion; $\mathrm{BIC}=$ Bayesian information criterion; $\mathrm{a}-\mathrm{BIC}=$ sample size adjusted BIC; BLRT = bootstrapped likelihood ratio test. 


\section{Table 3}

Latent class membership probabilities and item-response probabilities

\begin{tabular}{|c|c|c|c|c|}
\hline \multicolumn{5}{|l|}{ White $(n=592)$} \\
\hline Indicator & $\begin{array}{l}\text { Class 1: Always } \\
\text { Low }(1.95 \%)\end{array}$ & $\begin{array}{l}\text { Class 2: Upwardly } \\
\text { Mobile }(18.14 \%)\end{array}$ & $\begin{array}{l}\text { Class 3: Subjectively } \\
\text { Downward }(27.74 \%)\end{array}$ & $\begin{array}{l}\text { Class 4: Always High } \\
(52.17 \%)\end{array}$ \\
\hline \multicolumn{5}{|l|}{ Childhood SES } \\
\hline Parent graduated from HS/GED or higher $(\mathrm{O})$ & .18 & .43 & .78 & .91 \\
\hline Family of origin never received welfare $(\mathrm{O})$ & .52 & .79 & .92 & 1.00 \\
\hline High financial level growing up $(\mathrm{S})$ & .13 & .37 & .70 & .82 \\
\hline \multicolumn{5}{|l|}{ Adult SES } \\
\hline Some college or higher $(\mathrm{O})$ & .05 & .74 & .85 & .96 \\
\hline High income to poverty ratio $(\mathrm{O})$ & .00 & .97 & .79 & .96 \\
\hline High current financial status (S) & .00 & .86 & .22 & .93 \\
\hline Enough money to fulfill basic needs $(\mathrm{S})$ & .00 & .99 & .32 & .96 \\
\hline Not difficult paying bills (S) & .00 & .80 & .06 & .97 \\
\hline \multicolumn{5}{|l|}{ Black $(n=158)$} \\
\hline Indicator & $\begin{array}{l}\text { Class 1: Always } \\
\text { Low }(32.97 \%)\end{array}$ & $\begin{array}{l}\text { Class 2: Downwardly } \\
\text { Mobile }(35.84 \%)\end{array}$ & $\begin{array}{l}\text { Class 3: Subjectively } \\
\text { Always High }(6.48 \%)\end{array}$ & $\begin{array}{l}\text { Class 4: Objectively } \\
\text { Always High }(24.71 \%)\end{array}$ \\
\hline \multicolumn{5}{|l|}{ Childhood SES } \\
\hline Parent graduated from HS/GED or higher $(\mathrm{O})$ & .49 & .60 & .50 & .74 \\
\hline Family of origin never received welfare $(\mathrm{O})$ & .22 & 1.00 & .23 & .73 \\
\hline High financial level growing up (S) & .44 & .93 & .79 & .51 \\
\hline \multicolumn{5}{|l|}{ Adult SES } \\
\hline Some college or higher $(\mathrm{O})$ & .48 & 68 & .24 & $\mathbf{1 . 0 0}$ \\
\hline High income to poverty ratio $(\mathrm{O})$ & .36 & .52 & .19 & 1.00 \\
\hline High current financial status $(\mathrm{S})$ & .18 & .19 & .61 & .86 \\
\hline Enough money to fulfill basic needs (S) & .08 & .30 & 1.00 & .92 \\
\hline Not difficult paying bills (S) & .08 & .08 & .82 & .88 \\
\hline
\end{tabular}

Note: Boldface type indicates high probability for the indicator. $\mathrm{O}=$ objective indicator of SES; $\mathrm{S}=$ subjective indicator of SES 


\section{Table 4}

Expected mean of inflammation markers based on SES mobility among Whites and Blacks

\begin{tabular}{|c|c|c|c|c|c|}
\hline \multicolumn{6}{|l|}{ White $(n=592)$} \\
\hline \multirow[t]{3}{*}{ Outcome } & \multirow{3}{*}{$\begin{array}{l}\text { Omnibus } \\
\text { Test (Wald } \\
\chi^{2}, d f=3 \text { ) }\end{array}$} & Class 1: Always & Class 2: Upwardly & Class 3: Subjectively & \multirow{2}{*}{$\begin{array}{l}\text { Class 4: Always High } \\
(52.17 \%)\end{array}$} \\
\hline & & Low $(1.95 \%)$ & Mobile (18.14\%) & Downward $(27.74 \%)$ & \\
\hline & & Mean $\pm S E$ & & 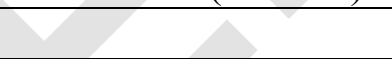 & \\
\hline IL-6 $(\log )$ & $17.44^{* * *}$ & $1.32 \pm 0.19^{b}$ & $0.79 \pm 0.11$ & $0.69 \pm 0.06$ & $0.55 \pm 0.05^{\mathrm{a}}$ \\
\hline CRP $(\log )$ & $15.08^{* *}$ & $0.97 \pm 0.28^{b}$ & $0.43 \pm 0.17$ & $0.37 \pm 0.09$ & $0.05 \pm 0.08^{a}$ \\
\hline sICAM-1 (log) & $12.89^{* *}$ & $5.83 \pm 0.12^{b}$ & $5.52 \pm 0.04$ & $5.58 \pm 0.03^{b}$ & $5.48 \pm 0.02^{\mathrm{a}}$ \\
\hline \multicolumn{6}{|l|}{ Black $(n=158)$} \\
\hline \multirow[t]{3}{*}{ Outcome } & \multirow{3}{*}{$\begin{array}{l}\text { Omnibus } \\
\text { Test (Wald } \\
\chi^{2}, d f=3 \text { ) }\end{array}$} & Class 1: Always & Class 2: Downwardly & Class 3: Subjectively & Class 4: Objectively \\
\hline & & Low $(32.97 \%)$ & Mobile $(35.84 \%)$ & Always High $(6.48 \%)$ & Always High (24.71\%) \\
\hline & & Mean $(S E)$ & & & \\
\hline IL-6 (log) & 4.38 & $1.16 \pm 0.10$ & $0.94 \pm 0.11$ & $0.86 \pm 0.27$ & $0.82 \pm 0.14$ \\
\hline CRP (log) & $7.22^{\dagger}$ & $1.15 \pm 0.20^{b}$ & $0.65 \pm 0.18$ & $1.13 \pm 0.51$ & $0.42 \pm 0.20$ \\
\hline sICAM-1 (log) & 2.79 & $5.47 \pm 0.08$ & $5.36 \pm 0.09$ & $5.51 \pm 0.35$ & $5.20 \pm 0.14$ \\
\hline
\end{tabular}

Note: $d f=$ degrees of freedom; $S E$ : Standard Error; ${ }^{*}: p<0.050,{ }^{* *}: p<0.010,{ }^{* * *}: p<.001,{ }^{\dagger}: p<0.1$; ${ }^{\text {a }}$ : Significantly lower than the overall group mean $(p<.05)$, : Significantly higher than the overall group mean $(p<0.05)$. 